\title{
Metodologia alternativa para condução do teste de envelhecimento acelerado em sementes de milho
}

\author{
Alternative methodology for the accelerated aging test for corn seeds \\ Sonia Regina Mudrovitsch de Bittencourt ${ }^{\mathrm{I}}$ Camila Ribeiro de Souza Grzybowski ${ }^{\mathrm{I}^{*}}$ \\ Maristela Panobianco"II Roberval Daiton Vieira ${ }^{\mathrm{III}}$
}

\section{RESUMO}

Os testes de vigor são rotineiramente empregados em programas internos de controle de qualidade por empresas sementeiras. Para tanto, é necessária a escolha de métodos eficientes que possibilitem a obtenção de respostas rápidas para a tomada de decisões relacionadas ao manuseio, descarte e comercialização dos lotes de sementes. A pesquisa objetivou verificar a redução do período de execução do teste de envelhecimento acelerado (EA) em sementes de milho, empregando-se, para a avaliação do desempenho das sementes após o envelhecimento, o teste de tetrazólio - TZ (viabilidade e vigor) em substituição ao de germinação (TG) em 10 lotes de sementes de sete genótipos de milho, com e sem tratamento fungicida. Os dados obtidos com a metodologia proposta $(E A+T Z)$ foram comparados com os valores determinados pelo teste de envelhecimento acelerado realizado com a metodologia tradicional $(E A+T G)$. $O$ uso do teste de tetrazólio (vigor), associado ao teste de envelhecimento acelerado, possibilitou a obtenção de informações semelhantes às fornecidas pelo teste de germinação empregado para o mesmo fim, reduzindo de oito para três dias o tempo necessário para a obtenção dos resultados em sementes de milho.

Palavras-chave: Zea mays, vigor, teste de tetrazólio.

\section{ABSTRACT}

Some vigor tests are routinely used by seed industry for internal programs of seed quality control. Then, it is requested the use of efficient methods to obtain quick answers to take right decisions related to the management, discard and trade of seed lots. This research was carried out in order to study the possibility to short the period to get the accelerated aging test (AA) results, using the tetrazolium test (TZ) instead of germination test (GT) to evaluate the seed performance after the seed aging. Tem corn seed lots were used, with and without fungicide treatment. The data obtained using the alternative method $(A A+T Z)$ were compared with those determined by the traditional one $(A A+G T)$. There was discrimination among seed lots using the traditional AA test and aging combined with $\mathrm{TZ}$ test. The corn seed vigor can be evaluate using the TZ test after seed aging instead of germination test. It allows similar results with the advantage of reducing the test period from eight to three days.

Key words: Zea mays, vigor, tetrazolium test.

\section{INTRODUÇÃO}

A alta qualidade das sementes reflete diretamente no resultado final da cultura (ANDREOLI et al., 2002), proporcionando uniformidade de população, alto vigor de plântulas e plantas (DIAS et al., 2010), ausência de patógenos transmitidos por sementes e, consequentemente, maior produção. Portanto, avaliações que permitam a obtenção de informações seguras sobre o potencial fisiológico das sementes são de importância fundamental para as decisões a serem tomadas durante o processo produtivo e de comercialização das mesmas.

As informações fornecidas pelo teste de germinação são consideradas insuficientes para, isoladamente, estimar o potencial de desempenho das sementes em condições de campo (OHLSON et al., 2010).

${ }^{\mathrm{I}}$ Ministério da Ciência e Tecnologia (MCT), Coordenação Geral de Mudanças Globais de Clima, Brasília, DF, Brasil.

"Departamento de Fitotecnia e Fitossanitarismo, Universidade Federal do Paraná (UFPR), 80035-050, Curitiba, PR, Brasil. Email: camilaribeirodesouza@gmail.com. *Autor para correspondência.

IIIDepartamento de Produção Vegetal, Universidade Estadual Paulista (UNESP), Jaboticabal, SP, Brasil. 
Dessa forma, as empresas produtoras de sementes têm utilizado, em conjunto com o teste de germinação, informações obtidas com testes de vigor; assim, é crescente a busca de testes que sejam rápidos para agilizar a tomada de decisões e aumentar a eficiência das atividades envolvidas no controle de qualidade.

A análise de sementes é ferramenta importante no controle de qualidade, principalmente a partir do final do período de maturação, quando as sementes atingem a maturidade fisiológica. Portanto, a seleção de testes de vigor deve atender a objetivos específicos, sendo importante a identificação das características avaliadas pelo teste e sua relação com o comportamento das sementes diante de situações específicas como, por exemplo, o desempenho após a secagem, o potencial de armazenamento, a resposta a injúrias mecânicas e as condições climáticas (BAALBAKI et al., 2009).

Dessa forma, as informações fornecidas pelos testes de frio e de envelhecimento acelerado fazem com que eles sejam considerados fundamentais para o gerenciamento da produção nos programas de controle de qualidade de sementes de milho (CASEIRO \& MARCOS FILHO, 2002; SOUZAet al., 2009). A resposta das sementes às condições adversas impostas pelos dois testes possibilita estimar o desempenho das sementes em uma faixa mais ampla de condições ambientais (MARCOS FILHO, 2005).

Os testes de frio e de envelhecimento acelerado demandam, respectivamente, 12 e oito dias (BARROS et al., 1999; MARCOS FILHO, 1999; DUTRA \& VIEIRA, 2004) para a obtenção dos resultados, uma vez que para a condução destes, inicialmente, as sementes de milho ficam expostas às condições adversas por determinado período, sete dias no teste de frio e três no envelhecimento acelerado e, em seguida realiza-se o teste padrão de germinação para avaliação de seu desempenho nessas condições (cinco dias).

Na literatura, há relatos de que as avaliações do potencial fisiológico das sementes por meio de testes que demandam período de tempo relativamente curto estão relacionadas a mudanças bioquímico-fisiológicas associadas ao vigor, como por exemplo, as atividades enzimáticas e respiratórias, cujas alterações podem ser identificadas nos tecidos do embrião pelo teste de tetrazólio (ABDUL-BAKI \& ANDERSON, 1973; MARCOS FILHO, 2005).

O teste de tetrazólio, além de fornecer informações sobre a viabilidade das sementes em poucas horas, fator fundamental em programas de controle de qualidade, possibilita também determinar o vigor, diferindo apenas nos critérios de avaliação empregados na avaliação das sementes (FRANÇA NETO \& KRZYZANOSKI, 2009).
Para sementes de milho, os resultados do teste de tetrazólio normalmente correspondem às porcentagens de plântulas normais obtidas em teste de germinação, realizado em condições altamente favoráveis, incluindo o tratamento fungicida (DIAS \& BARROS, 1999). Em pesquisa realizada por BARROS \& DIAS (1995), verificou-se que o teste de tetrazólio foi eficiente para identificar lotes de sementes de milho com diferentes níveis de potencial fisiológico, quando comparado a outros testes de vigor, inclusive com a emergência de plântulas em campo.

Em razão da importância do teste de envelhecimento acelerado no sistema de produção de sementes de milho, o trabalho objetivou verificar a redução do período de execução do teste de envelhecimento acelerado em sementes de milho, empregando-se o teste de tetrazólio (viabilidade e vigor) em substituição ao teste de germinação na avaliação do desempenho das sementes após o seu envelhecimento.

\section{MATERIAL E MÉTODOS}

O experimento foi conduzido no Laboratório de Análise de Sementes do Departamento de Produção Vegetal, da UNESP, Campus de Jaboticabal - SP, com amostras de 10 lotes de sementes de milho obtidos junto a empresas do setor, com e sem tratamento fungicida, sendo dois lotes dos híbridos 8501, 8452 e XL-360 e um lote dos híbridos C-125, C-606, BR-201 e BR-205. As amostras de sementes que constituíram os lotes experimentais dos híbridos 8501 e 8452 receberam tratamento fungicida realizado pela própria empresa produtora, com Captan + Thiabendazole $(120+20 \mathrm{~g}$ de i.a. $100 \mathrm{~kg}^{-1}$ de sementes) e corante Rodamina. Os lotes de sementes dos demais genótipos foram tratados manualmente com os fungicidas Carboxin + Thiran (60+60g de i.a. $100 \mathrm{~kg}^{-1}$ de sementes).

$\mathrm{O}$ teor de água inicial das sementes foi determinado pelo método de estufa a $105 \pm 3^{\circ} \mathrm{C}$ por 24 horas (BRASIL, 2009), com quatro repetições de 20 sementes por tratamento. Nas avaliações realizadas sem tratamento fungicida, as amostras dos 10 lotes de sementes foram submetidas ao envelhecimento acelerado (EA), o qual foi conduzido em caixas de plástico (11,0x11,0x3,5cm), distribuindo-se camada única de sementes sobre a tela de inox interna às caixas, de modo a cobri-la completa e uniformemente (MARCOS FILHO, 1999). As caixas contendo $40 \mathrm{~mL}$ de água destilada no fundo foram tampadas e mantidas em câmara de envelhecimento tipo jaquetada de água (VWR Scientific, modelo 3015 ), a $45^{\circ} \mathrm{C}$ durante 72 horas (DUTRA \& VIEIRA, 2004; BITTENCOURT \& VIEIRA, 2006). 
Decorrido o período de envelhecimento, as sementes foram retiradas da câmara, submetidas à determinação do teor de água e, em seguida, divididas em três subamostras, sendo que numa delas foi realizada a metodologia padrão para avaliação do vigor pelo envelhecimento acelerado, ou seja, com o teste de germinação (TG), conduzido com quatro repetições de 50 sementes para cada rolo de papel toalha umedecido com água, na quantidade equivalente a 2,5 vezes a massa do substrato seco, a $25^{\circ} \mathrm{C}$, avaliando-se as plântulas normais no quinto dia após a instalação do teste (MARCOS FILHO, 1999; BRASIL, 2009).

As outras duas subamostras foram usadas para a condução da metodologia alternativa, utilizando o teste de tetrazólio (TZ) no lugar do teste de germinação. Após o período de envelhecimento, as sementes foram submetidas a duas formas de pré-condicionamento: em água a $30^{\circ} \mathrm{C}$ por meia hora e em papel toalha umedecido a $30^{\circ} \mathrm{C}$ por duas horas. Em seguida, quatro repetições de 20 sementes por subamostra foram utilizadas para a determinação do teor de água e quatro repetições de 50 sementes foram seccionadas longitudinalmente, sob lupa com aumento de seis vezes e iluminação circular fluorescente, selecionando a metade com as estruturas embrionárias visíveis e descartando-se a outra. Após o preparo, as partes selecionadas das sementes de cada subamostra foram imersas em solução de tetrazólio
0,075\% por uma hora a $35^{\circ} \mathrm{C}$. Decorrido esse período, estas foram retiradas da solução de tetrazólio, lavadas em água corrente e avaliadas de acordo com os critérios de viabilidade e vigor determinados por DIAS \& BARROS (1995).

Procedimentos semelhantes foram realizados com amostras dos mesmos lotes de sementes tratadas com fungicida; porém, para o teste de tetrazólio (viabilidade e vigor) empregou-se o pré-condicionamento em água a $30^{\circ} \mathrm{C}$ por 0,5 hora.

O delineamento experimental utilizado foi o inteiramente casualizado, com quatro repetições; os testes de envelhecimento acelerado associados aos testes de tetrazólio (EA+TZ) realizados com sementes não tratadas foram instalados em esquema fatorial 10x2 (lotes e condições de embebição). Nas análises estatísticas, os dados obtidos com os testes de envelhecimento acelerado foram transformados em arc sen nx/100, utilizando-se o teste de Tukey a 5\% de probabilidade para a comparação das médias.

\section{RESULTADOS E DISCUSSÃO}

Na tabela 1, estão os dados referentes à avaliação do vigor pelo teste de envelhecimento acelerado (EA), conduzido em associação com os testes de germinação (TG) e de tetrazólio (TZ) -

Tabela 1 - Potencial fisiológico (\%) de 10 lotes de sementes de milho, sem tratamento fungicida, obtido pelo teste de germinação (TG) e teste de envelhecimento acelerado com avaliação por meio dos testes de germinação (EA+TG) e de tetrazólio (EA+TZ-viabilidade), com pré-condicionamento das sementes em água e em papel.

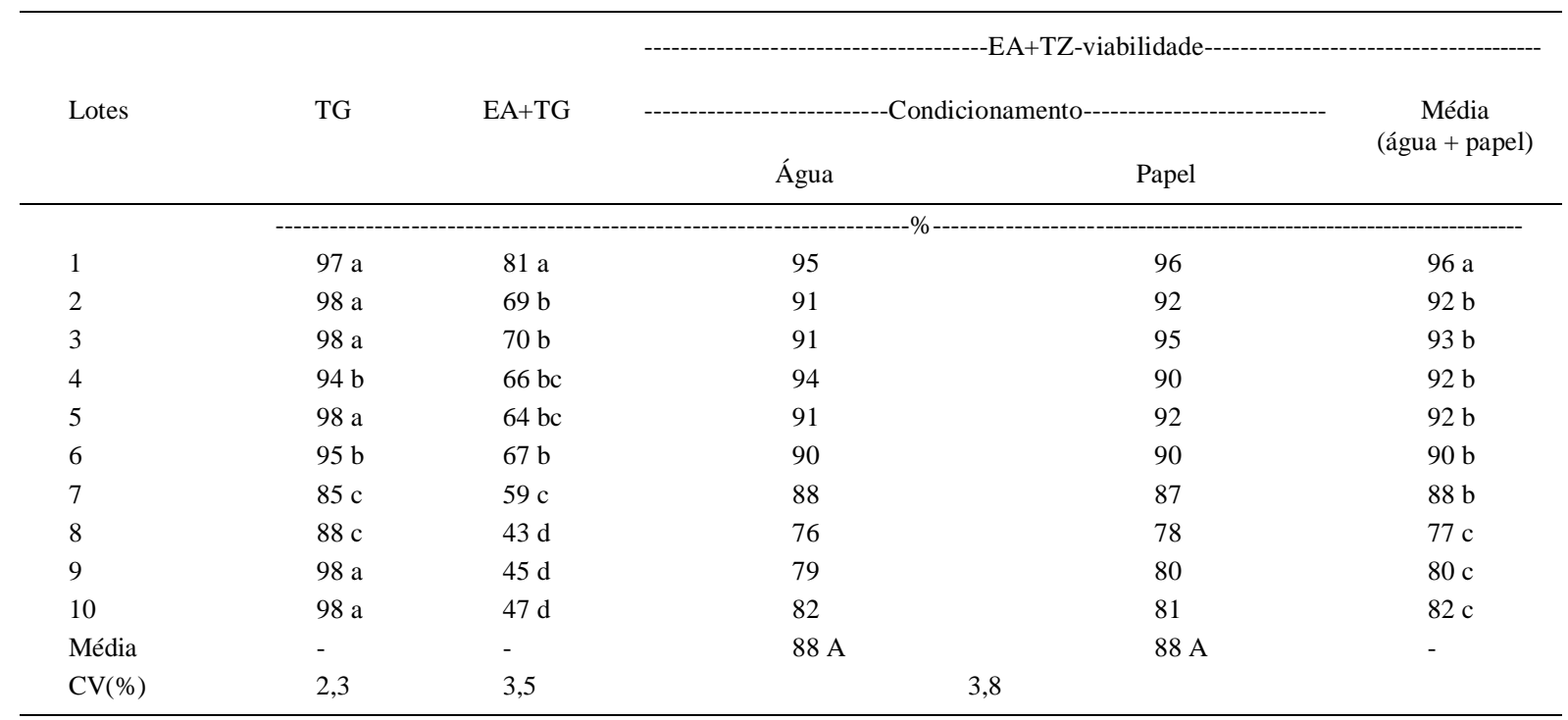

Médias seguidas pela mesma letra minúscula nas colunas (em todos os testes) e maiúscula nas linhas (EA+TZ-viabilidade) não diferem entre si pelo teste de Tukey a 5\% de probabilidade.

Nas médias, estão os valores originais, porém para a análise estatística, os dados foram transformados em arc sen vx/100.

Ciência Rural, v.42, n.8, ago, 2012. 
viabilidade, para sementes de milho sem tratamento fungicida. Independentemente dos testes usados (germinação ou tetrazólio) para indicar o comportamento fisiológico das sementes após condições de temperatura e umidade relativa do ar elevadas (envelhecimento acelerado), os resultados obtidos foram semelhantes, ou seja, pelo teste de germinação, o lote 1 foi significativamente superior aos lotes 2, 3, 4, 5, 6 e 7, que, por sua vez, foram superiores aos lotes 8, 9 e 10, classificados como de baixo potencial fisiológico. Pelos resultados do teste de tetrazólio, pode-se verificar também o comportamento superior do lote 1 e inferior dos lotes 8, 9 e 10, ficando os demais lotes com níveis intermediários de vigor.

Quanto aos dois processos de précondicionamento avaliados, os dados da tabela 1 demonstraram que não houve resposta diferenciada das sementes causadas pela embebição em água ou em papel, indicando a possibilidade de empregarem-se ambos os procedimentos para o pré-condicionamento das sementes após o envelhecimento, sem prejuízos na coloração e visualização das estruturas essenciais durante a avaliação do teste.

Os resultados do teste de EA+TZ-vigor (Tabela 2) indicaram, de forma semelhante às informações obtidas com os testes de EA+TG e de EA+TZ-viabilidade (Tabela 1), o lote 1 como de maior vigor e os lotes 8, 9 e 10 como de pior desempenho, verificando-se porém separação mais detalhada dos lotes de sementes com médio e baixo vigor, indicada pelo teste de EA+TZ-vigor.

Para os resultados do EA+TZ-vigor, também não se constataram diferenças estatísticas entre si em função do tipo de pré-condicionamento usado para o processo de coloração das sementes (Tabela 2). Ao se analisar os dados das tabelas 1 e 2 , verifica-se que os testes usados na avaliação do comportamento das sementes frente às condições impostas pelo envelhecimento acelerado foram unânimes na diferenciação dos lotes com potencial fisiológico elevado daqueles de desempenho deficiente, o que segundo MARCOS FILHO (1999) é um dos objetivos principais dos testes de vigor.

Na tabela 3, encontram-se os valores de vigor das amostras de sementes tratadas com fungicida, pelos quais se observa que a classificação das sementes pelo teste de envelhecimento acelerado (metodologia tradicional) diferiu daquela obtida com as sementes não tratadas (Tabelas 1 e 2), ocorrendo o agrupamento das médias em função do tratamento fungicida. Esses resultados indicaram que não é possível a comparação de resultados do teste de envelhecimento acelerado entre lotes e/ou amostras de sementes de milho tratadas e sem tratamento fungicida, ou seja, a comparação deve ocorrer entre

Tabela 2 - Potencial de vigor (\%) de 10 lotes de sementes de milho, sem tratamento fungicida, obtido pelo teste de envelhecimento acelerado com avaliação por meio dos testes de germinação (EA+TG) e de tetrazólio (EA+TZ-vigor), com pré-condicionamento das sementes em água e em papel.

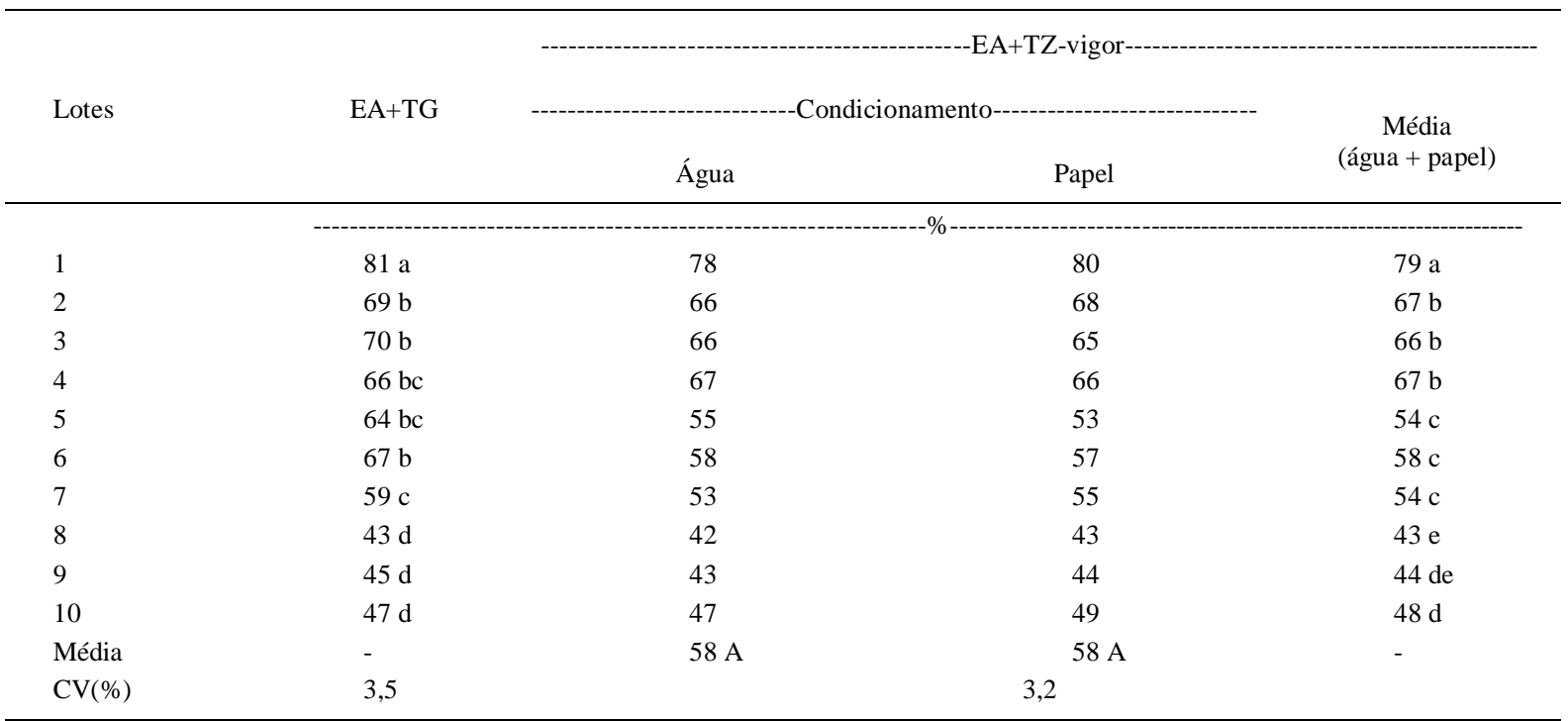

Médias seguidas pela mesma letra minúscula nas colunas (em todos os testes) e maiúscula nas linhas (EA+TZ-viabilidade) não diferem entre si pelo teste de Tukey a $5 \%$ de probabilidade.

Nas médias, estão os valores originais, porém para a análise estatística os dados foram transformados em arc sen vx/100. 
Tabela 3 - Potencial fisiológico (\%) de 10 lotes de sementes de milho, tratadas com fungicida, obtido pelo teste de germinação (TG) e teste de envelhecimento acelerado com avaliação por meio dos testes de germinação (EA+TG) e de tetrazólio (EA+TZ-viabilidade e EA+TZ-vigor), com o pré-condicionamento das sementes em água.

\begin{tabular}{|c|c|c|c|c|}
\hline Lotes & TG & $\mathrm{EA}+\mathrm{TG}$ & EA+TZ-viabilidade & $\mathrm{EA}+\mathrm{TZ}$-vigor \\
\hline & ------- & ------- & -------------\%--------- & - \\
\hline 1 & 98 a & 92 a & 94 a & 86 a \\
\hline 2 & $97 \mathrm{a}$ & $91 \mathrm{a}$ & $91 \mathrm{a}$ & $84 \mathrm{a}$ \\
\hline 3 & $98 \mathrm{a}$ & $91 \mathrm{a}$ & $94 \mathrm{a}$ & $84 \mathrm{a}$ \\
\hline 4 & $94 \mathrm{~b}$ & $87 \mathrm{a}$ & 93 a & $80 \mathrm{a}$ \\
\hline 5 & $98 \mathrm{a}$ & $78 \mathrm{~b}$ & $90 \mathrm{a}$ & $72 \mathrm{~b}$ \\
\hline 6 & $92 \mathrm{~b}$ & $86 \mathrm{a}$ & $92 \mathrm{a}$ & 80 a \\
\hline 7 & $84 \mathrm{c}$ & 74 bc & $92 \mathrm{a}$ & $64 \mathrm{c}$ \\
\hline 8 & $87 \mathrm{c}$ & $70 \mathrm{c}$ & $90 \mathrm{a}$ & $61 \mathrm{c}$ \\
\hline 9 & $97 \mathrm{a}$ & $54 \mathrm{~d}$ & $89 \mathrm{ab}$ & $50 \mathrm{~d}$ \\
\hline 10 & $98 \mathrm{a}$ & $48 \mathrm{~d}$ & $83 \mathrm{~b}$ & $46 \mathrm{~d}$ \\
\hline $\mathrm{CV}(\%)$ & 2,1 & 3,3 & 3,3 & 3,4 \\
\hline
\end{tabular}

Médias seguidas pela mesma letra na coluna não diferem entre si pelo teste de Tukey a 5\% de probabilidade.

Nas médias, estão os valores originais, porém para a análise estatística os dados foram transformados em arc sen vx/100.

lotes tratados e sem tratamento. Resultados semelhantes foram encontrados por TEKRONY (1996) avaliando o efeito do tratamento fungicida em sementes de milho sobre os resultados do teste de envelhecimento acelerado.

Com base nos dados obtidos, o teste de EA+TZ-viabilidade não foi eficiente na classificação dos lotes de sementes tratadas com fungicida, observando-se tendência de agrupamento dos resultados (Tabela 3). Nessa condição, o vigor dos lotes 1 a 8 foi semelhante entre si e superior ao do lote 10 $(\mathrm{P}>0,05)$, enquanto o lote 9 foi classificado como de qualidade intermediária.

Tal fato se justifica, uma vez que os critérios do teste de tetrazólio-viabilidade baseiam-se na identificação de tecidos mortos ou deteriorados presentes em regiões vitais do embrião, que condicionam desde a produção de plântulas anormais até a morte das sementes. Esses sintomas manifestamse nos estádios finais da deterioração, que pode ser acelerada pela presença de patógenos, principalmente fungos, os quais produzem toxinas que causam desde necrose em tecidos até a inibição da germinação (MATTHEWS, 1985; BEWLEY, 1986).

Por outro lado, nos testes de EA+TG e de EA+TZ-vigor (Tabela 3) os resultados foram semelhantes, sendo que os lotes 1, 2, 3, 4 e 6 foram classificados com os de alta qualidade, não sendo observadas diferenças estatísticas de vigor entre eles. Os valores dos lotes 9 e 10, classificados na categoria de mais baixo vigor foram semelhantes entre si $(\mathrm{P}>0,05)$; os demais lotes (5, 7 e 8) são de níveis intermediários de vigor, com destaque para o lote 5 , cujo valor foi o mais alto dentro da categoria.

A maior eficiência observada no teste de tetrazólio-vigor, para sementes tratadas com fungicida pode ser devido ao fato de os critérios usados na avaliação dos níveis de vigor serem mais rigorosos do que na determinação da viabilidade, incluindo aspectos relacionados não só à dimensão da área lesionada, mas também à localização da lesão em relação ao eixoembrionário.

O teor de água das sementes dos 10 lotes estudados (com ou sem tratamento fungicida) antes e após o envelhecimento acelerado foi semelhante, variando de 11,2 a $11,7 \%$ e de 25,4 a $26,0 \%$, respectivamente; comportamento semelhante foi verificado após o condicionamento das sementes em água (28,3 a 29,7\%) e em papel (28,3 a 29,2\%). As diferenças de teor de água detectadas dentro de cada variável avaliada não ultrapassaram os valores máximos aceitos como determinantes da precisão dos resultados no teste de envelhecimento acelerado (MARCOS FILHO, 1999; AOSA, 2002).

\section{CONCLUSÃO}

O uso do teste de tetrazólio-vigor associado ao teste de envelhecimento acelerado em sementes de milho, com ou sem tratamento fungicida, possibilita obter informações semelhantes às fornecidas pelo teste de germinação empregado para o mesmo fim. 


\section{AGRADECIMENTOS}

Ao Conselho Nacional de Desenvolvimento Científico e Tecnológico $(\mathrm{CNPq})$ e à Fundação de Amparo à Pesquisa do Estado de São Paulo (Fapesp), pelo apoio, bolsa de pesquisa e auxílio financeiro.

\section{REFERÊNCIAS}

ABDUL-BAKI, A.A.; ANDERSON, J.D. Vigor determination in soybean seed by multiple criteria. Crop Science, v.13, n.6, p.630-633, 1973.

ANDREOLI, C. et al. Influência da germinação da semente e da densidade de semeadura no estabelecimento do estande e na produtividade de milho. Revista Brasileira de Sementes, v.24, n.2, p.1-5, 2002. Disponível em: <http://www.scielo.br/ pdf/rbs/v24n2/v24n2a01.pdf $>$. Acesso em: 10 abr. 2011. doi: 10.1590/S0101-31222002000100001.

ASSOCIATION OF OFFICIAL SEED ANALYSTS. Seed vigor testing handbook. Lincoln, 2002. 105p. (Contribution 32).

BAALBAKI, R. et al. Seed vigor testing handbook. Ithaca, New York: Association of Official Seed Analysts, 2009. 346p. (Contribution 32 to the Handbook on Seed Testing).

BARROS, A.S.R.; DIAS, M.C.L.L. O teste de tetrazólio para avaliação da qualidade fisiológica das sementes de milho. Informativo ABRATES, v.5, n.2, p.159, 1995.

BARROS, A.S.R. et al. Teste de frio. In: KRZYZANOWSKI, F.C. et al. (Ed.). Vigor de sementes: conceitos e testes. Londrina: ABRATES, 1999. p.5 (1-15).

BEWLEY, J.D. Membrane changes in seeds as related to germination and perturbations resulting from deterioration in storage. In: McDONALD JR.; NELSON, C.J. (Ed.). Physiology of seed deterioration. Madison: Crop Science Society of America, 1986. p.27-46.

BITTENCOURT, S.R.M.; VIEIRA, R.D. Temperatura e período de exposição de sementes de milho no teste de envelhecimento acelerado. Revista Brasileira de Sementes, v.28, n.3, p.161168, 2006. Disponível em: <http://www.scielo.br/pdf/rbs/v28n3/ 23.pdf $>$. Acesso em: 5 abr. 2011. doi: 10.1590/S010131222006000300023 .

BRASIL. Ministério da Agricultura, Pecuária e Abastecimento. Regras para análise de sementes. Ministério da Agricultura, Pecuária e Abastecimento. Secretaria de Defesa Agropecuária. Brasília, DF: MAPA /ACS, 2009. 395p.
CASEIRO, R.F.; MARCOS FILHO, J. Procedimentos para condução do teste de frio em sementes de milho: pré-resfriamento e distribuição do substrato no interior da câmara fria. Revista Brasileira de Sementes, v.24, n.2, p.6-11, 2002. Disponível em: <http://www.scielo.br/pdf/rbs/v24n2/v24n2a02.pdf>. Acesso em: 10 abr. 2011. doi: 10.1590/S010131222002000100002 .

DIAS, M.C.L.L.; BARROS, A.S.R. Metodologia de teste de tetrazólio em sementes de milho. In: KRZYZANOWSKI, F.C. et al. (Ed.). Vigor de sementes: conceitos e testes. Londrina: ABRATES, 1999. p.8.4 (1-10).

DIAS, M.A.N. et al. Vigor de sementes de milho associado à mato-competição. Revista Brasileira de Sementes, v.32, n.2, p.93-101, 2010. Disponível em: <http://www.scielo.br/ pdf/rbs/v32n2/v32n2a11.pdf>. Acesso em: 11 abr. 2011. doi: 10.1590/S0101-31222010000200011.

DUTRA, A.S.; VIEIRA, R.D. Envelhecimento acelerado como teste de vigor para sementes de milho e soja. Ciência Rural, v.34, n.3, p.715-721, 2004. Disponível em: <http:// www.scielo.br/pdf/cr/v34n3/a10v34n3.pdf>. Acesso em: 5 abr. 2011. doi: 10.1590/S0103-84782004000300010.

FRANÇA NETO, J.B.; KRZYZANOWSKI, F.C. Seed vigor tests: general procedures - Tetrazolium vigor test. In: BAALBAKI, R.Z. et al. (Ed.). Seed vigor testing handbook. Ithaca, NY, USA: AOSA, 2009. p.227-306. (Contribution n.32).

MARCOS FILHO, J. Teste de envelhecimento acelerado. In: KRZYZANOWSKI, F.C. et al. (Ed.). Vigor de sementes: conceitos e testes. Londrina: ABRATES, 1999. p.3 (1-24).

MARCOS FILHO, J. Fisiologia de sementes de plantas cultivadas. Piracicaba: FEALQ, 2005. 495p.

MATTHEWS, S. Physiology of seed ageing. Outlook on Agriculture, v.14, n.2, p.89-94, 1985.

OHLSON, O.C. et al. Teste de envelhecimento acelerado em sementes de trigo. Revista Brasileira de Sementes, v.32, n.4, p.118-124, 2010. Disponível em: <http:// homolog.scielo.br/pdf/rbs/v32n4/13.pdf $>$. Acesso em: 5 abr. 2011. doi: 10.1590/S0101-31222010000400013.

SOUZA, S.A. et al. Teste de envelhecimento acelerado em sementes de aveia preta. Revista Brasileira de Sementes, v.31, n.2, p.155-163, 2009. Disponível em: <http:// www.scielo.br/pdf/rbs/v31n2/v31n2a18.pdf $>$. Acesso em: 11 abr. 2011. doi: 10.1590/S0101-31222009000200018.

TEKRONY, D.M. Accelerated aging test conditions for hybrid corn seed. Lowa Seed Science, v.16, n.2, p.3-4, 1996. 